\title{
Regional temperature and humidity monitoring via mobile sensor nodes
}

\section{Mobil algılayıcı düğümler vasıtasıyla bölgesel ısı ve nem takibi}

\author{
Şenol Zafer ERDOĞAN+1 (iD), Mustafa Önder GEREN² (D) \\ 1Department of Computer Engineering, Faculty of Engineering and Architecture, Konya Food \& Agriculture University, Konya, \\ Turkey. \\ senol.erdogan@gidatarim.edu.tr \\ ${ }^{2}$ Department of Computer Engineering, Faculty of Engineering and Natural Sciences, Maltepe University, Istanbul, Turkey. \\ ondergeren@gmail.com
}

\section{Abstract}

Due to the latest developments in mobile and ubiquitous computing, it is feasible to deploy environment monitoring sensors using a large number of mobile devices. In this paper, we propose a system to continuously monitor a particular region's temperature and humidity. The "server" is a center point (base station) that collects the data. The sensor nodes deliver the data to the server at a given schedule or on demand. The server is equipped with the data visualization tools for conducting visual analytics on the collected sensor data. The proposed system consists of three modules. The first module consists of the mobile sensor devices to monitor the region's temperature and humidity. General Packet Radio Services (GPRS) and GPS module are integrated in the nodes. Further, for continuous and responsive monitoring, there is a real-time communication with these mobile sensor nodes. The second module consists of the components to collect data from the sensor nodes and record the data in the server database. Finally, the third module provides the data mining and data visualization on the recorded data in server database. The proposed system is implemented and tested on several bus routes in Istanbul, Turkey. The results show that the proposed system could be beneficial in developing precise models for the environment monitoring.

\section{Introduction}

In recent years, wireless technologies and communication means are used in academic and commercial sectors. Wireless Sensor Network (WSN) is one of the rapid-growing fields in wireless technologies. WSNs are used in many areas such as military, system security, environment and habitat monitoring [1], health-care [2], localization, elder and disabled people monitoring [3], smart homes etc. WSN consist of smart devices known as sensors (motes or nodes). The sensor nodes have limited computing, storage and energy sources. The sensor nodes can communicate with each other using the radio modules and they can create an ad-hoc self-organized network that can provide intelligent, pervasive and ubiquitous applications, Akyildiz et al [4]. For wireless communication, IEEE 802.15.4 ZigBee protocol is commonly used to address the unique needs of low-cost and low power WSNs [5],[6]. Further, the sensor node contains a sensor board, which senses the readings such as temperature, humidity, light, acoustic, seismic, gas etc.

In traditional WSNs, the sensor devices use the radio module integrated on the processing board to transfer the data; however, in the proposed system, the GPRS and the GPS (Global

\section{Öz}

Mobil ve yaygın hesaplama alanlarındaki en son gelişmeler nedeniyle çevreyi izleyen algılayıcılara sahip çok sayıda mobil algılayıcı cihazların yerlestirilmesi uygun olmaktadır. Bu çalıșmada, belirli bir bölgenin Isı ve nemini sürekli takip eden bir sistem önerilmektedir. Sunucu, veriyi toplayan merkez noktasıdır. Algılayıcı düğüm, verilen bir takvim veya istek üzerine sunucuya veriyi göndermektedir. Sunucu, toplanan algılayıcı verileri için veri görselleștirme araçlarıyla donatılmıştır. Önerilen sistem üç modülden oluşmaktadır. Ilk modül bölgenin ISI ve nemini takip eden mobil algılayıcl cihazdan olușmaktadır. GPRS ve GPS modülleri bu düğümlere bütünleștirilmiștir. Ayrıca, sürekli ve duyarlı izlemek için bu mobil algılayıcı düğümlerle gerçek zamanlı bir iletișim vardır. Íkinci modül algılayıcı düğümlerden veri toplama ve sunucu veritabanında veriyi kaydeden bileşenleri içerir. Son olarak üçüncü modül, sunucu veritabanında kayıtlı veriler üzerinde veri madenciliği ve veri görselleștirmeyi sağlar. Önerilen sistemin kodu geliştirildi ve İstanbul'daki çeşitli otobüs güzergâhlarında test edildi. Sonuçlar, önerilen sistemin çevreyi izleme için kesin modeller geliștirmede yararlı olabileceğini göstermektedir

Anahtar kelimeler: Algılayıcı, Veri madenciliği, Takip

Positioning System) modules are integrated into the sensor device and the GPRS module is used for communication between sensor devices. The Global Positioning System is a US. space-based radio navigation system that provides reliable positioning, navigation, and timing services for civilian users on a continuous worldwide basis (it is freely available to the public). For anyone with a GPS receiver, the system will provide location and time. The GPS provides accurate location and time information for unlimited number of people regardless of the time, weather conditions or place throughout the world [7].

This paper presents an implementation of a WSN for environment monitoring where the sensor nodes monitor a particular region's temperature and humidity. While monitoring the region, the sensor devices sense the values and transfer the data to a center point via GPRS (General Packet Radio Services) connection. Eventually, the end user can access the data.

The sensors continuously send the readings via GPRS. After the readings reach the center point, it is recorded in the database. Furthermore, data visualization and data mining studies are performed on the recorded data. In the proposed system, the data is collected by the mobile sensor nodes that use GSM network to send the data to the central point. Although mobile 
sensor node requires high-energy consumption because of GPRS and GPS modules, the energy is obtained from the vehicle's battery; thus, energy consumption is not an issue for the mobile sensor node; the energy efficiency is not considered in this paper.

The remaining paper is organized as follows: Section 2 discusses the related works. Section 3 describes the mobile sensor node and the explanation of hardware specifications of the mobile sensor node. Section 4 provides the design of the proposed system and Section 5 provides the specific details of the components that are involved in the system. The evaluation of the proposed system is explained in Section 6. Finally, Section 7 concludes the paper.

\section{Related work}

There is active research in monitoring using WSNs. The Code Blue project at Harvard uses WSNs for medical applications [8]. In [2], system architecture is proposed based on WSN that targets assisted-living residents; ZigBee compliant (802.15.4) wireless protocols is used for the data communication between the sensor and the server. All sensors in a radio range cover all of the facility.

Veerasingam et al. [5] propose a portable wireless data logging system for temperature monitoring, where the center point receives the data, which is recorded in a file; all the sensors and the center point are in the radio range.

Crowley et al. [9] propose a system which describes the implementation of a WSN for the temperature monitoring over the Internet. However, in the proposed system, sensors transmit the data through radio frequency to a base station. The base station sends the data to a central server via the GSM network.

Duchkov et al. [10] design instruments for long-duration temperature monitoring and record bottom temperatures in the Lake Baikal. Autonomous temperature recorder is used to measure the temperature.

Zhengzhong et al. [11] propose a WSN monitoring system for living environment. The system monitors indoor environment and transmits the readings to database server by a wireless connection. The readings recorded in the database server can be viewed using PC or PDA devices.

Jin et al. [12] present a water monitoring system based on WSNs. The system has three parts: a) sensor nodes, b) sink nodes, and c) data monitoring center. Further, the network has a two-layer hierarchy. The sensor nodes in the lower layer sample the water environment data and send the data to the sink nodes. Then, the sink nodes in the higher layer send data to the monitoring center using a local or remote communication. The system presents the real time monitoring system for measuring the water quality.

Bayilmis et al. [13] propose a web based remote monitoring system for WSNs using Matlab web server. The system provides variety of features such as reading storage collected from the sensors, displaying, analyzing them by using Matlab and server components. In addition, users can connect to the system by using any internet enabled devices (i.e., PC, smart phones, PDA)

In most of the WSN related studies, the sensor nodes communicate with each other via ZigBee wireless protocol. Furthermore, the base station is in the radio transmission range of sensors and these sensors can transfer the data to the base station. As the base station is connected to an existing wired infrastructure, the collected sensor data can be transferred to a distant center point for further processing.

The main differences of the study presented in this article from the studies summarized above are given below:

- Sensor readings are collected from the vehicles which move constantly,

- Location information of collected readings are known,

- Due to collecting readings from different locations constantly, scientific discovery of regional weather similarities of different locations can be achieved.

- $\quad$ Establishment of this proposed system to all public transport system, weather similarities of the different regions of Turkey can be discovered.

\section{Mobile sensor node}

A sensor node called the mobile sensor node is used in this paper. The mobile sensor node senses the readings and transfers them to the center point via GPRS connection. Sensor devices use the IEEE 802.15.4 protocol, but the mobile sensor node uses the GPRS connection to transfer the data to remote locations. The mobile sensor node consists of 3 modules as shown in Figure 1. The GPS and the GPRS modules are packed in Cinterion's XT65 device. The sensor board module is used to sense the readings.

Mobile Sensor Node

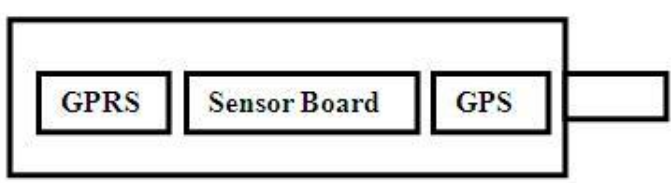

Figure 1: The Mobile sensor node structure.

The mobile sensor node senses the readings and transfers them via a GPRS connection to the center point. Figure 2 shows the pseudo code of the algorithm to obtain the sensor readings and to send the readings via the GPRS connection. First, the readings are obtained; then the packet is assembled and prepared for transfer. Finally, the packet is sent by calling the send function of the GPRS module. Although the GPS requires high-energy consumption, the GPS integrated mobile sensor node is attached to a vehicle and it obtains the energy from the vehicle's battery. The mobile sensor node can be attached to any vehicle and it can continuously collect the sensor readings. As a result, the mobility for the sensor node is achieved by using the mobility of the vehicles.

procedure SensorReadCode()
1: Read Temperature Value
2: Read Humidity Value
3: String sendPacket="AT Command String"
4: String valuesString=FloatToString(Temperature Value) +
FloatToString(Humidity Value);
5: sendPacket=sendPacket+valuesString;
6: call send(sendPacket) to GPRS module;

Figure 2: Pseudo code for SensorRead to send data via the GPRS connection. 
The mobile sensor node's hardware specifications are as follows:

- The Sensor Board: The sensor board is used to sense the temperature and humidity readings. There are several sensor boards which sense light, seismic, vibration, gas, ultrasonic etc. Several companies have different sensor boards. Suitable sensor boards can be used in specific application areas. The proposed system uses Moteiv Tmote Sky sensor motes that have temperature and humidity sensors and CC2420 Chipcon 802.15.4 radio,

- The GPRS Module: Cinterion's XT65 wireless module is integrated into the sensor node. XT65 GPRS module provides Quad-Band GSM850/900 /1800/1900 MHz and the Internet Services: TCP, UDP, HTTP, FTP, SMTP, and POP3. The GPRS is a packet-based wireless communication service that provides data rates from 56 up to $114 \mathrm{Kbps}$. It provides a continuous connection to the Internet for computer users or mobile devices. The mobile sensor node uses the GPRS module to transfer the readings,

- The GPS Module: Cinterion's XT65 wireless module has 16 channel receivers L1 $1575.42 \mathrm{MHz}$, GPS dedicated AT commands and Protocols: NMEA-0183 V2.3, RTCM protocol V2.2, UBX binary protocol. The GPS module in the mobile sensor node provides information about location and time. The mobile sensor agent senses the temperature and humidity on a specific schedule. The information about the temperature and humidity of a specific location and time is collected.

The mobile sensor node sends the following information to the server: a) temperature and humidity readings from Telosb, b) GPS location data, and c) time stamp. The CPU executes the application developed with $\mathrm{j} 2 \mathrm{me}$ programming language. J2me (Java Micro Edition) is a Java-based library developed by Oracle (Sun Micro Systems) for mobile devices. The J2me library consists of fundamental java classes and j2me classes that are able to run on the mobile devices.

The mobile sensor node can also execute AT commands. The AT stands for ATtention. The AT commands are used for programming and communication of modem devices.

\section{System architecture}

The proposed system measures the temperature and humidity readings via the mobile sensor nodes existing on the vehicles. The vehicles with sensor nodes tour the desired geographical region and data are collected. There is no energy issue in the system because the energy can be obtained from the vehicle's battery.

Figure 3 shows architecture of the proposed system. The mobile sensor node exists on the vehicle. The mobile sensor node reads temperature and humidity values, the GPS location of environment and timestamp on a given schedule. The sensor data is sent to the server via the Internet using the GSM infrastructure. The server collects the data and records the data in the database. There are four components in the server: the message listener, the data manager, the knowledge extract manager, and the database.

1. The Message Listener: The message listener acts like a bridge. It listens to the data packets sent through the
Internet by the sensor nodes and sends them to the data manager.

2. The Data Manager: The data manager saves temperature, humidity, location and time data sent from the message listener module to the database. It executes the queries that are sent to the knowledge extraction manager to create the temperature and humidity maps and sends the results of the queries to the knowledge extraction manager,

3. The Knowledge Extraction Manager: The knowledge extraction manager processes the data obtained from the database using knowledge extraction and clustering (K-Means) algorithms. It creates timedependent temperature and humidity maps,

4. Database: The data is stored in database because it is easy to execute queries and filter the data. The data is used to create temperature and humidity time-dependent maps of regions using knowledge extraction and data mining (clustering) algorithms. $\mathrm{K}$-Means algorithm is used as a clustering algorithm in this paper.

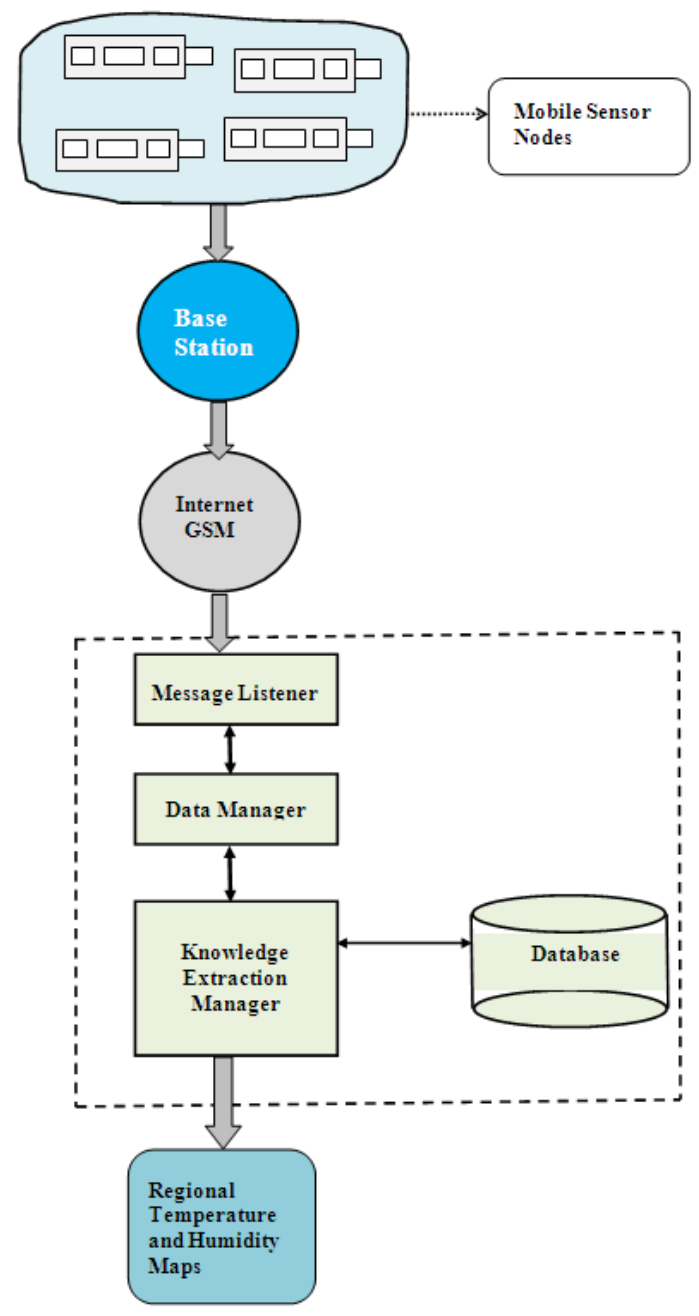

Figure 3: System architecture.

\section{XT65App application}

The application named XT65App is developed in Java programming language by using j2me classes. The XT65App 
application reads the mobile sensor node's location information sent from the GPS module and temperature and humidity readings sent from TelosB sensor. The XT65App sends the data to the IP address and port number specified in the configuration file. The XT65App application repeats the sending and reading processes in a period specified in configuration file.

The XT65App application consists of three classes:

- The Connection class: It defines functions that send the data to the server application. It is developed to send the measured readings sent from Telosb to the base station via the XT65 wireless module.

- The ReadSensor class: It defines functions that read the data sent from Telosb sensor. It is developed to read the data sent from TelosB via XT65 wireless module.

- The XT65App class: It defines functions that manage the application. It is the main class of the XT65App application. The XT65App class controls the XT65 wireless module's processes. At the beginning of the application, it is created to start the execution. The XT65App class reads the configuration file to obtain server IP address, port number, and schedule (duration) of reading and sending processed values.

The TelosB App application is developed on TelosB node to read temperature and humidity readings and sends them to the XT65 wireless module through expansion port on a given schedule.

\section{Experiments}

The mobile sensor node is deployed in a vehicle that follows the specific bus route across Istanbul, Turkey to collect temperature and humidity readings. The route is represented in Figure 4. The distance travelled is approximately $47 \mathrm{~km}$. It took approximately 83 minutes to traverse the route and record 501 sample readings (10 seconds/sample). While travelling the route, the mobile sensor node senses the readings and transfers the data to the center point via GSM.

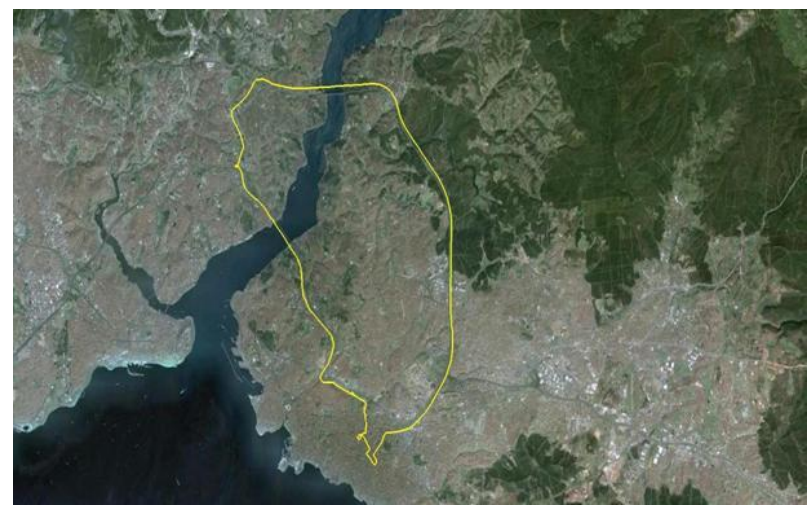

Figure 4: The Route in Istanbul.

The knowledge extraction manager processes the collected data using knowledge extraction and clustering (K-Means) algorithm. The clustering analysis (K-Means algorithm) is run on the collected 501 samples data. The K-means algorithm is executed with $\mathrm{k}=2$ value. The created clusters are represented in Figure 5. The X-axis and Y-axis represent the GPS coordinates of the samples in Figure 5.

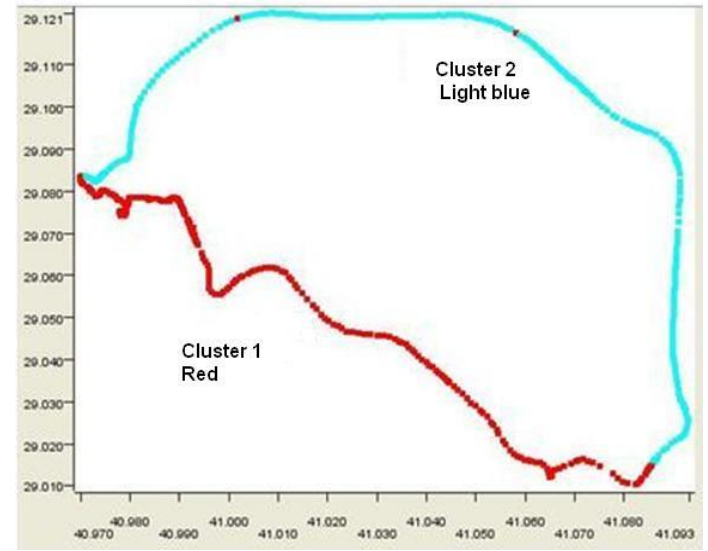

Figure 5: Clustering with $\mathrm{k}=5$.

In Figure 5, the red points belong to the first cluster and the light blue points to the second cluster. When the red points are projected to the route represented in Figure 4, we see that the red points are on the south-southeast part of the geographical area. The blue points are on the north-northwest part. We are able to see that the red points are close to the sea, and the blue points are close to inland.

The K-means algorithm is also executed with $\mathrm{k}=3$ and $\mathrm{k}=4$ values and results obtained are presented in Figure 6 and Figure 7, where each color represents a different cluster.

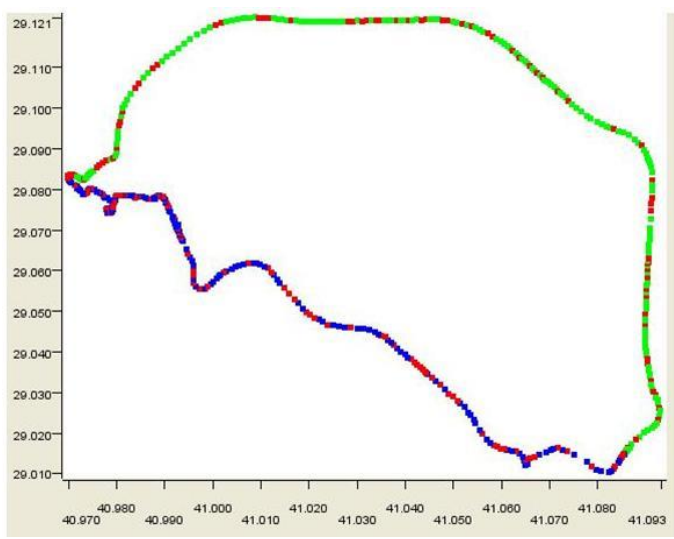

Figure 6: Clustering with $\mathrm{k}=3$.

As presented in Figure 6 and Figure 7, the clusters are not clear. So the clustering with $\mathrm{k}=2$ is more appropriate for the obtained data.

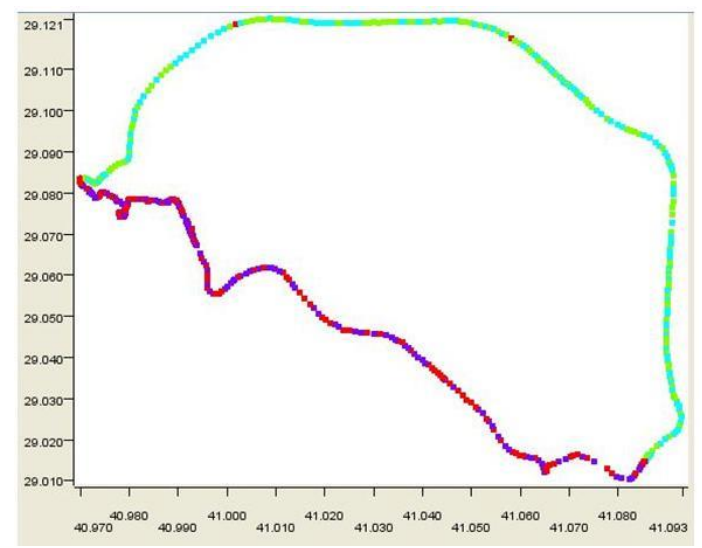

Figure 7: Clustering with $\mathrm{k}=4$. 
Table 1 shows the average values of temperature and humidity of both clusters $(\mathrm{k}=2)$. The total sample numbers of each cluster are close to each other; however, the difference between the average temperature values is 0.137 and the difference between the average humidity values of is 5.056. According to the calculated values, the humidity values are more distinctive than temperature values while determining the two clusters. The area close to the sea, which is represented by cluster 2 , shows higher humidity values and the inner area, which is represented by cluster 1 , shows lower humidity values. It shows that humidity values play an important role in distinguishing the clusters.

Table 1: Average values for 2 clusters.

\begin{tabular}{ccc}
\hline & $\begin{array}{c}\text { Cluster 1 } \\
\text { (Red) }\end{array}$ & $\begin{array}{c}\text { Cluster 2 (Light } \\
\text { Blue) }\end{array}$ \\
\hline Average temperature & 13.893 & 14.03 \\
Average humidity & 52.179 & 57.235 \\
$\begin{array}{c}\text { Total number of } \\
\text { samples }\end{array}$ & 245 & 256 \\
\hline
\end{tabular}

In another experiment, the vehicle equipped with mobile sensor node covers a wider geographical area. The route includes Kavacik, Levent, Taksim, Besiktas, Sisli and Kadikoy (Hasanpasa - Erenkoy) regions. Figure 8 shows the route of the data collected.

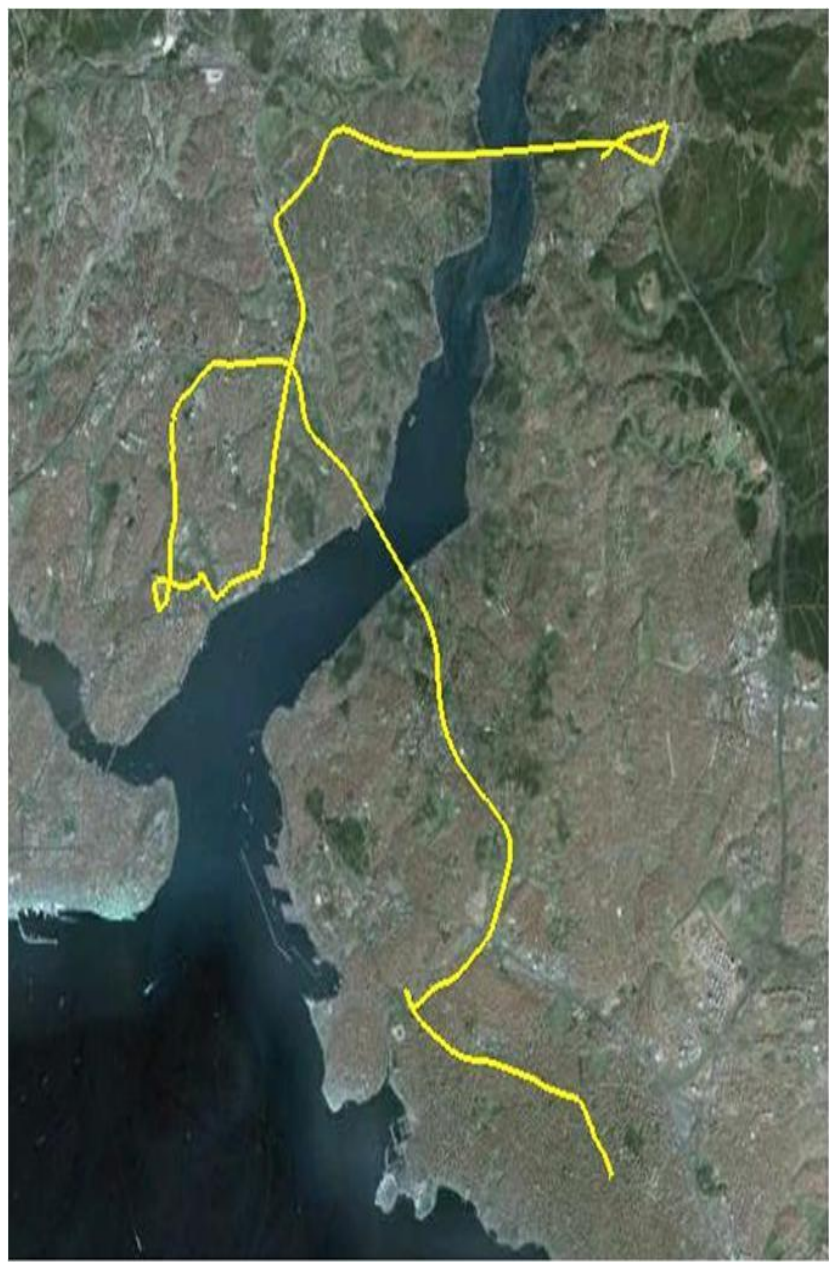

Figure 8: Data collection route-2.
543 data samples of location, temperature and humidity are collected in 5-second intervals on the route shown in Figure 8. The distance travelled is approximately $47 \mathrm{~km}$. It took approximately 45 minutes to traverse the route and record 543 sample readings ( 5 seconds/sample).

The 543 data samples collected are analyzed using K-means algorithm. Two clusters are created in the first analysis in which K-means algorithm is executed with the value of $\mathrm{K}=2$. The clusters are shown in Figure 9. The X-axis and Y-axis represent the GPS coordinates of the samples in Figure 9.

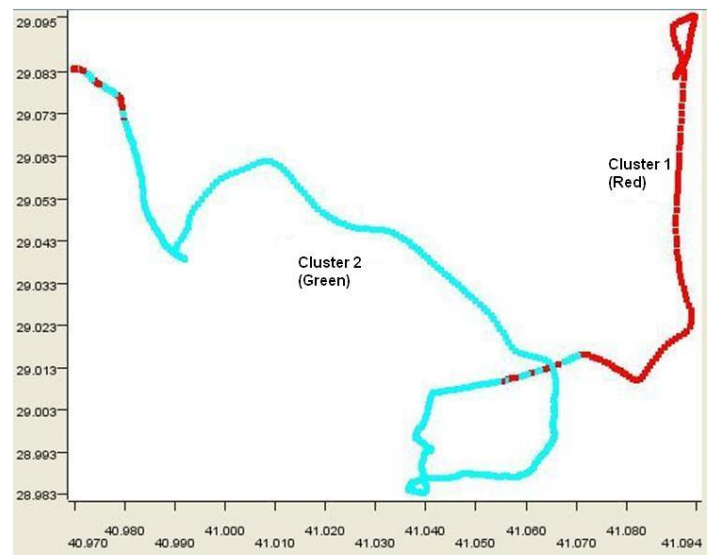

Figure 9: Results of the 2-clustering.

The K-means algorithm with $\mathrm{k}=3$ and $\mathrm{k}=4$ is executed on the data collected and the results are shown in Figure 10 and Figure 11 respectively, where ach color represents a different cluster.

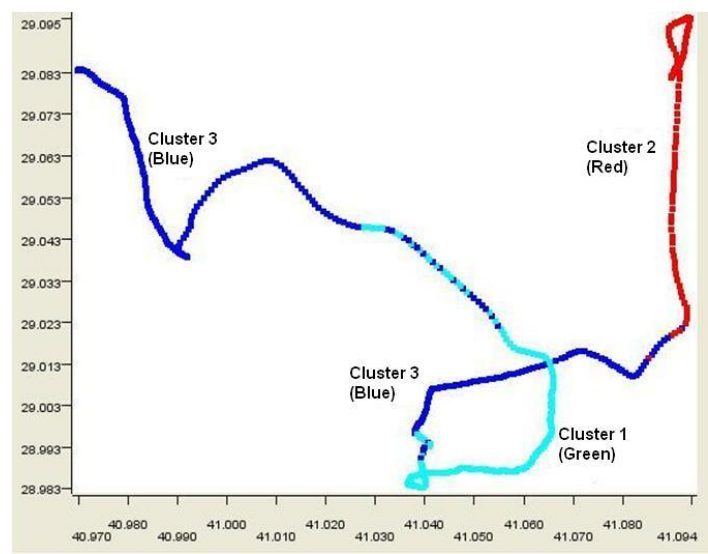

Figure 10: Results of the 3-clustering.

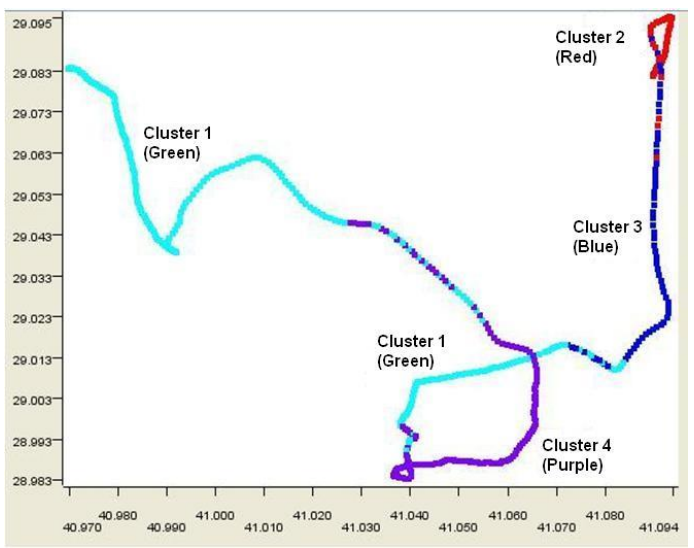

Figure 11: Results of the 4-clustering. 
As the result of the clustering with $\mathrm{k}=3$ and $\mathrm{k}=4$, clusters are clearly separated. Therefore, the 3-clustering and 4-clustering are analyzed. Table 2 shows the average temperature and humidity values obtained from the 3 -clustering analysis. The cluster 2, which is colored with red, has the highest average humidity value. This region is between Kavacik-Levent areas and close to Fatih Sultan Mehmet Bridge and to the sea. The region that is close to the sea shows high humidity value. As shown in Figure 10, the two different regions colored with blue in Cluster 3 have similar temperature and humidity values.

Table 2: The 3-clustering analysis.

\begin{tabular}{cccc}
\hline & $\begin{array}{c}\text { Cluster 1 } \\
\text { (Green) }\end{array}$ & $\begin{array}{c}\text { Cluster 2 } \\
\text { (Red) }\end{array}$ & $\begin{array}{c}\text { Cluster 3 } \\
\text { (Blue) }\end{array}$ \\
\hline $\begin{array}{c}\text { Average } \\
\text { Temperature }\end{array}$ & 7.56 & 5.04 & 6.23 \\
$\begin{array}{c}\text { Average } \\
\text { Humidity }\end{array}$ & 64.43 & 73.74 & 68.48 \\
\hline
\end{tabular}

The results of the K-means algorithm executed with $\mathrm{k}=4$ are shown in Figure 11. Table 3 shows the average temperature and humidity values obtained from the 4-clustering analysis. Similarities based on the temperature and humidity values, belonging to two different regions, in the 3-clustering (Besiktas(Barbaros bulvari) ve Kadikoy(Hasanpasa- Erenkoy) ) are also shown in the 4-clustering analysis. As shown in Table 3, cluster 2 and cluster 3 have the highest humidity levels. These two clusters, which represent Kavacik-Levent area, are also shown in the 3 -clustering analysis as cluster 2 (red color) in Figure 10.

Table 3: The 4-clustering analysis.

\begin{tabular}{ccccc}
\hline & $\begin{array}{c}\text { Cluster } \\
1 \\
\text { (Green) }\end{array}$ & $\begin{array}{c}\text { Cluster } \\
2 \\
\text { (Red) }\end{array}$ & $\begin{array}{c}\text { Cluster } \\
\text { (Blue) }\end{array}$ & $\begin{array}{c}\text { Cluster } \\
4 \\
\text { (Purple) }\end{array}$ \\
\hline $\begin{array}{c}\text { Average } \\
\text { Temperature }\end{array}$ & 6.8 & 5.0 & 5.39 & 7.49 \\
Average Humidity & 66.7 & 74.5 & 72.0 & 64.8 \\
\hline
\end{tabular}

Sisli region is located in a separate cluster in both the 3 clustering and 4-clustering. Sisli region is the inner region. Sisli is shown in green and purple in Figure 10 and Figure 11, respectively. As a result of both clustering processes, presentation of Sisli region as a separate cluster shows that the region has significant differences as compared to the other regions.

\section{Conclusion}

In this paper, location, temperature and humidity values are collected by a mobile sensor node traveling in a specific region. The values collected are sent to a server via the internet through the GPRS protocol using GSM infrastructure.

Although temperature and humidity values are collected with the proposed system, the work can be extended to collect different environmental values (CO sensor, light sensor, $\mathrm{CO} 2$ sensor), which can be collected and sent to the server for further processing. The time-dependent air pollution maps of the region can also be extracted. Thus, we can create more accurate and precise environment models in real time. Further, the data and maps can be created for different sampling periods. The temperature and humidity values of the sub-area of the region can be obtained on a seasonal, monthly, or weekly basis. By using the data mining and clustering algorithms on the collected sensor data, different geographic regions that have similar environmental features can be identified. The collected sensor data using mobile sensor nodes can assist in predicting more accurate weather forecast.

\section{References}

[1] Mainwaring A, Mainwaring A, Polastre J, Polastre J, Szewczyk R, Szewczyk R, Culler D, Culler D. "Wireless sensor networks for habitat monitoring". 1st ACM International Workshop on Wireless Sensor Networks and Applications, Atlanta, Georgia, USA, 28 September, 2002.

[2] Virone G, Wood A, Selavo L, Cao Q, Fang L, Doan T, He Z, Stoleru R, Lin S, Stankovic JA. "An advanced wireless sensor network for health monitoring". Transdisciplinary Conference on Distributed Diagnosis and Home Healthcare (D2H2), 2006

[3] Ergen SC. "Zigbee/ieee 802.15.4 summary". University of California Berkeley, Technical Report, California, USA, 10 September 2004.

[4] Victor Shnayder, Bor-rong Chen, Konrad Lorincz, Thaddeus R. F. Fulford-Jones, and Matt Welsh, "Sensor Networks for Medical Care", Harvard University, Technical Report, Massachusetts, USA, April 2005.

[5] Veerasingam S, Karodi S, Shukla S, Yeleti MC. "Design of wireless sensor network node on zigbee for temperature monitoring". International Conference on Advances in Computing, Control, and Telecommunication Technologies, Trivandrum, India, 28-29 December 2009.

[6] Duchkov A, Kazantsev S, Duchkov A. "Bottom temperature monitoring in Lake Baikal". Russian Geology and Geophysics, 48, 371-377, 2007.

[7] Fern'andez-Luque F, Zapata J, Ruiz R, Iborra E. "A wireless sensor network for assisted living at home of elderly people". $3^{\text {rd }}$ International Work-Conference on The Interplay Between Natural and Artificial Computation, Santiago de Compostela, Spain, 22-26 June 2009.

[8] Ali ASB, Money WH. "A study of project management system acceptance". 38th Annual Hawaii International Conference on System Sciences, Big Island, HI, USA, 6 January 2005.

[9] Akyildiz I, Su W, Sankarasubramaniam Y, Cayirci E. "A survey on sensor networks". IEEE Communication Magazine, 40, 102-114, 2002.

[10] Crowley K, Frisby J, Murphy S, Roantree M, Diamond D. "Web-based real-time temperature monitoring of shellfish catches using a wireless sensor network". Sensors and Actuators A: Physical, 122(2), 222-230, 2005.

[11] Zhengzhong W, Zilin L, Jun L, Xiaowei H. "Wireless sensor networks for living environment monitoring". 2009 WRI World Congress on Software Engineering, Xiamen, China, 19-21 May 2009.

[12] Official U.S. government information about the Global Positioning System (GPS) and related topics. "Global Positioning System". http://www.gps.gov/, (12.04.2010).

[13] Bayilmis C, Cakiroglu M, Ozturk SS, Cankaya I. "Development of web based remote monitoring system for wireless sensor networks using matlab web server". Journal of the Faculty of Engineering and Architecture of Gazi University, 25(2), 371-379, 2010. 